Fifth International Conference on Sustainable Construction Materials and

Technologies. http://www.claisse.info/Proceedings.htm

\title{
METABOLISM OF METALS FROM CO-PROCESSING OF ENERGY-FROM-WASTE AIR POLLUTION CONTROL RESIDUE IN CEMENT KILNS
}

\author{
Marchand, L. ${ }^{1}$, Van Ewijk, S. ${ }^{2}$, Stegemann, J. A. ${ }^{2}$ \\ ${ }^{1}$ Department of Civil, Environmental, and Geomatic Engineering, ETH Zurich \\ ${ }^{2}$ Centre for Resource Efficiency \& the Environment, University College London
}

\begin{abstract}
Co-processing of air pollution control residues (APCR) from energy-from-waste (EfW) facilities in the cement kiln is a potential alternative to landfill and an opportunity to reduce the virgin raw material demand of cement production. However, the high concentrations of trace metals and soluble salts in these residues are of concern. In the present work, material and substance flow analyses were conducted to estimate the potential effects of co-processing raw and washed APCR from UK EfW facilities as alternative raw materials for cement manufacture on the metal concentrations in cement powder. The results suggest that co-processing APCR can significantly increase the concentration of several toxic trace metals in cement, but may decrease the concentration of others (e.g., Tl) whose background concentrations in virgin raw materials typically used in the UK are higher than those in APCR. The high chlorine concentration in APCR leads to a disproportional increase in the fraction of raw gas bypassed from recirculation to the preheater, from 1 to $81 \%$, when the co-processed amount is increased from 0 to $35 \%$ of the raw materials. This effect can be mitigated by pre-washing of APCR. However, loss of soluble salts during water washing increases the concentrations of insoluble trace metals in the residue ( $\mathrm{Co}, \mathrm{Cr}, \mathrm{Mn}, \mathrm{Ni}$ and $\mathrm{V}$ ), and, thus, cement. The collection of more UK-specific data would increase the robustness of the model and life cycle assessment of the different disposal options (landfilling, co-processing with and without washing) could help develop sustainable policies regarding the fate of APCR.
\end{abstract}

Keywords: Air pollution, cement kiln, trace metals, energy-from-waste

\section{INTRODUCTION}

Cement manufacture requires large amounts of minerals and fossil fuels and leads to significant environmental impacts. Co-processing of alternative raw materials (ARM) in cement kilns can reduce virgin material requirements and decreases volumes of waste to landfill (Stegemann 2014). However, the toxic metal contents of many ARM are higher than those of virgin materials and these can escape from the cement life cycle into the environment. As such, there is a need for evidence regarding the potential impacts of using ARM.

This paper focuses on co-processing of Energy-from-Waste (EfW) Air Pollution Control Residue (APCR), which has been the subject of trials at bench to commercial scale (Stegemann et al., 2019). This type of residue contains fly ash and acid gas cleaning products that are removed from flue gases from municipal solid waste combustion. It has relatively high levels of potential pollutants, such as zinc and lead, and soluble anions, such as chlorides and 
sulphates, whereby the latter can be removed by water washing (Bogush, Stegemann, and Roy 2019).

The objective of this work was to examine the potential effect of co-processing APCR and washed APCR (w-APCR) on the trace metal concentrations in UK cement clinker, cement kiln dust (CKD), bypass dust (BPD) and cement powder, using Material Flow Analysis (MFA) and Substance Flow Analysis (SFA). The work is part of a research collaboration between the China Building Materials Academy, South China University of Technology and University College London, which aims to examine the fate of toxic metals contained in wastes in co-processing in the cement kiln, from the waste, to the cement clinker, by-product dusts, cement paste, and concrete.

The paper proceeds as follows. The next section explains our data sources and modelling approach. The results are then presented and show the effect of different proportions of APCR and w-APCR in the raw material mix on trace metal flows. A sensitivity analysis is conducted to help understand the effects on the model of the fraction of clinker kiln dust (CKD) recovered on-site and the amount of raw gas from the kiln purged with the bypass. Finally, the discussion section deals with implications of the results and possible improvements regarding the calculations in the model.

\section{METHODS}

\subsection{Frame and Scope}

The present work attempts to model the fate of fourteen trace metals in cement manufacture, and the impact of different proportions of APCR in the raw materials on the trace metal concentrations in cement powder. The fourteen trace metals are: arsenic (As), cadmium $(\mathrm{Cd})$, cobalt $(\mathrm{Co})$, chromium $(\mathrm{Cr})$, copper $(\mathrm{Cu})$, mercury $(\mathrm{Hg})$, manganese $(\mathrm{Mn})$, nickel $(\mathrm{Ni})$, lead $(\mathrm{Pb})$, antimony $(\mathrm{Sb})$, tin $(\mathrm{Sb})$, thallium $(\mathrm{Tl})$, vanadium $(\mathrm{V})$ and zinc $(\mathrm{Zn})$.

The temporal system boundary is the year 2015. This reference was chosen as quantitative data about cement production in the UK are available for this year, and were used in the construction of the base model, except where otherwise stated. Figure 1 shows the model structure and the system boundaries. The flows comprised in the model and the sub-flows that constitute the flows are shown in Table 1.

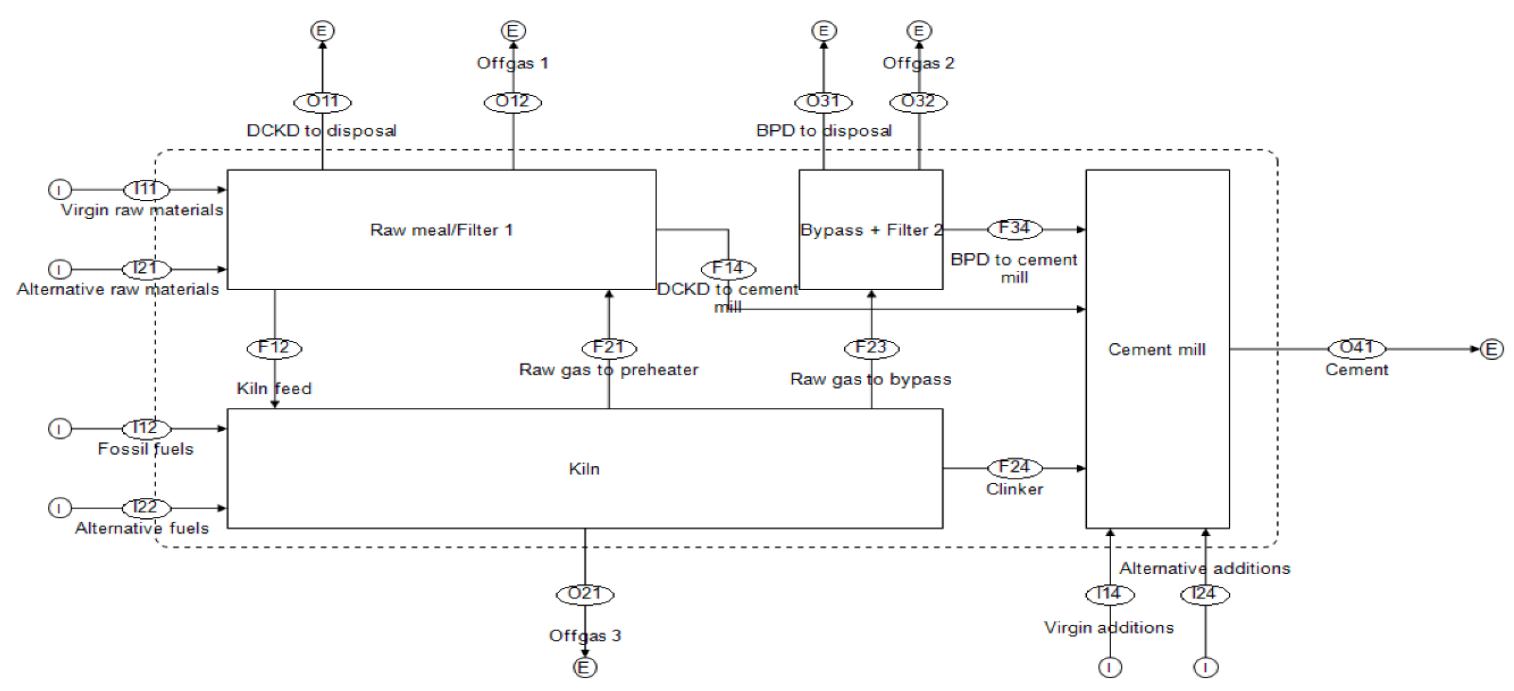


Figure 1: Model structure and system boundary.

Cement manufacture comprises two main stages. In the first step, clinker is manufactured from virgin materials (I11) and ARM, such as limestone, chalk, clay, pulverised fuel ash (PFA), quarry washings and others (I21), which are homogenised in a raw mill to make raw meal (i.e., kiln feed, F12). The process of sintering the raw meal in a kiln to form clinker is called clinkerisation. The model depicts the manufacture of clinker in a kiln equipped with a calciner and a suspended preheater.

The raw gas from the kiln is used to heat the kiln feed in the preheater $(\mathrm{F} 21)$ or is purged by the bypass (F23). The exhaust gas from the preheater can follow two routes.

- In compound operation, which represents $\sim 80 \%$ of the total kiln operating time over the course of the base year, the exhaust gas from the preheater is used to heat the raw meal in the raw mill. The raw meal works as a filter and particles are retained within the mill and the remaining gas sent to a filtering device.

- In direct operation, the exhaust gas from the preheater is cooled down before being directly exhausted through a filtering device when the raw mill is deactivated. The solids retained in the filtering device during compound operation are known as compound clinker kiln dust (CCKD), which is not shown in Figure 1, as the model assumes it to be completely recycled into clinker. The filtered solids during direct operation are identified separately in the model as direct clinker kiln dust (DCKD).

In Figure 1, compound and direct operation takes place in the process "Raw meal/Filter 1", which also includes the preheater. The DCKD and BPD are either disposed of (O11 and O31) or interground with clinker (F14), virgin (I14) and alternative (I24) additions to form cement (O41).

In the second step, cement powder is manufactured from clinker, and various virgin and alternative additions, including gypsum, and recycled BPD, CCKD, DCKD, and/or PFA (Table 1). These elements are ground together in a cement mill, in which no chemical reactions occur. Since the present work aimed at describing trace metal fate in UK cement manufacture, imports of clinker and cement powder were not taken into account in the mass balance.

Offgas $3(\mathrm{O} 21)$ was calculated separately and is composed of process $\mathrm{CO}_{2}$ and organic compounds, which can enter the kiln with fuels and are volatilized during clinkerisation. In reality, there is only one gas phase, which exits the kiln either via the preheater or the bypass. 
Table 1: Flows and sub-flows of the model.



\subsection{Material and Substance Flow Analysis}

MFA was chosen as an appropriate method to compute the flows of trace metals in cement manufacture in the base year (2015). MFA is a mass balance based on the principle of conservation of mass in a system over a defined timeframe, enabling the modelling of flows and stock changes.

Two different levels of mass balance modelling can be distinguished in the present work. The first level contains flows of materials, such as fossil and alternative fuels, virgin materials and ARM, clinker, CKD, BPD and cement powder; this level can be referred to as MFA. The flows in the second level are those of elements (14 trace metals and chlorine) and form the SFA. In the present report, the word "material" always refer to the first level of the model, while "substance" refers to the second level. The relationship between the flow of a material $F_{i}$ and the flow of a substance $F_{j}$ is described in Equation 1, where $c_{j, i}$ is the concentration of substance $\mathrm{j}$ in material $\mathrm{i}$.

$$
F_{j}=c_{j, i} \cdot F_{i} \quad \text { Equation } 1
$$




\subsection{Determination of Mass Flows}

Data about the input flows, and the production rates of clinker and cement powder in the UK were mainly obtained from the Mineral Products Association (MPA), a trade organisation representing UK cement producers. From the input flows, transfer coefficients allowed the computation of the other material flows through the system. The transfer coefficients are applied to the mass of an input flow, to calculate the mass flows of outputs, as shown in Figure 2. In the present work, transfer coefficients for both MFA and SFA were mainly taken from the updated guideline from Dr. Graf AG (Dr. Graf AG 1998) whose values were updated in 2004 (Neosys AG, personal communications, 18.1.2019). The transfer coefficients for the overall material and the fourteen trace metal flows, except $\mathrm{Mn}$ and $\mathrm{V}$, were obtained from Neosys AG. A comparison with the default transfer coefficients present in the LCA4Waste model showed that both $\mathrm{Mn}$ and $\mathrm{V}$ seem to have the same behaviour as $\mathrm{Co}, \mathrm{Cu}$ and $\mathrm{Ni}$. Because $\mathrm{Co}, \mathrm{Cu}$ and Ni do not have exactly the same transfer coefficients in the guideline (Dr. Graf AG 1998), the average of the transfer coefficients of the three was taken for both Mn and V. Table 1 in support information $\mathrm{S} 1$ lists the transfer coefficient values.



Figure 2: Effect of a transfer coefficient linked to a process 1 on an input 1 .

\subsection{Modelling the Bypass}

The materials that are introduced into clinker manufacture as raw materials or fuels sometimes contain elements that can interfere with the production processes. One of these elements is chlorine $(\mathrm{Cl})$, which is introduced as chloride $\left(\mathrm{Cl}^{-}\right)$into the kiln, where it substantially volatilises. $\mathrm{Cl}$ contained in the raw gas leaving the kiln via the preheating system precipitates with the cooler kiln feed and re-enters the kiln with the preheated raw materials, where the higher temperatures lead to its re-volatilisation, and circulation with the raw gas to the preheating system (Lanzerstorfer 2016). If nothing is done to prevent this, the amount of $\mathrm{Cl}$ in the system continues to increase (as more $\mathrm{Cl}$ enters the system than $\mathrm{Cl}$ leaves it) and will ultimately lead to lower mineral melting points and unacceptable changes in the clinkerisation process.

A bypass can be used to purge raw gas from the kiln at a point where the concentration of $\mathrm{Cl}$ in the gas is high, to maintain viable steady state $\mathrm{Cl}$ amounts in the system. Because the amount of $\mathrm{Cl}$ entering the process depends on the fuels and raw materials, the modelling calculates the amount of raw gas that is bypassed as a function of the $\mathrm{Cl}$ inputs. Thus, not only the trace metals concentrations and flows, but also the $\mathrm{Cl}$ concentrations and flows in the system are relevant to the modelling. Because the mass balance depicts the production of cement in the UK, it was important to obtain $\mathrm{UK}$-specific $\mathrm{Cl}$ concentrations for all the input materials in clinker manufacture. These were mainly obtained from five trial reports provided by the MPA. The default values in the cement kiln module from the LCA4waste model were used when no UKspecific data could be found. LCA4Waste is a model that was developed at the ETH in Zürich (Boesch, Vadenbo, and Hellweg n.d.) and whose cement kiln module allows the computation 
of mass flows of various elements, including $\mathrm{Cl}$. The default concentration values of $\mathrm{Cl}$ in clay, chalk and limestone were used.

The inputs and outputs of $\mathrm{Cl}$ over the annual basis used in the modelling were assumed to be equal, to calculate the amount of raw gas purged with the bypass. The $\mathrm{Cl}$ concentrations in BPD and CKD were fixed based on UK-specific values. The median of these values was used for the reference scenario (S_Ref in Table 2), depicting the situation in 2015. In the other scenarios, the $\mathrm{Cl}$ concentrations in BPD and DCKD were increased (or decreased) proportionally to the increase (or decrease) in $\mathrm{Cl}$ input, with respect to the reference scenario. The minimum (when the $\mathrm{Cl}$ inputs were lower than in S_Ref) and maximum (when the $\mathrm{Cl}$ inputs where higher than in S_Ref) values found in the literature were set as limits for the $\mathrm{Cl}$ concentrations in BPD and DCKD. With these settings, the model could react as follow to changes of $\mathrm{Cl}$ inputs, as the $\mathrm{Cl}$ concentrations in BPD and CKD were fixed:

- Increased $\mathrm{Cl}$ inputs $\rightarrow$ increased dust collection

- Decreased $\mathrm{Cl}$ inputs $\rightarrow$ decreased dust collection

The amount of raw gas directed to the bypass was then calculated by using the generalized reduced gradient method, implemented in the Microsoft Excel solver and aiming at minimizing the difference between $\mathrm{Cl}$ inputs and outputs.

It is important to note that not all the cement plants in the UK are equipped with a bypass. According to the Department for Environment, Food and Rural Affairs (Defra), four cement plants in the UK collect BPD and two collect CKD (Amec Foster Wheeler Environment 2015) to regulate the amount of $\mathrm{Cl}$ in the system.

\subsection{Determination of Trace Metals Concentrations}

Trace metal concentrations in the input flows were needed to calculate the flows of trace metals in the manufacture of cement in the UK (Equation 1). The data about trace metals concentrations in the usual inputs (I11, I21, I12, I22, I14 and I24) were taken from five trial reports of cement works in the UK that the cement companies submitted to the Environment Agency to obtain new permits for the use of alternative fuels. The concentration data for the APCR were taken from Bogush et al. (2015), which reports the composition of APCR from six EfW facilities in the UK; one of the facilities gave three samples, obtained at three different times. Minimum, maximum and median values were calculated from the 8 values obtained for each trace metal, except $\mathrm{Hg}$. $\mathrm{Hg}$ concentrations and w-APCR compositions were obtained from Bogush et al. (2019), which analysed samples from the same facility that gave three samples for the APCR analysis, using three different techniques: X-ray fluorescence, inductively coupled plasma spectroscopy and aqua regia digestion. Minimum, maximum and median values for each trace metal were calculated.

For the fossil fuel flows (I12), UK-specific data could be found for every trace metal. For alternative fuels (I22), UK-specific data could be found for most of the trace metals and subflows. UK-specific values could not be found for $\mathrm{Cd}, \mathrm{Co}, \mathrm{Hg}, \mathrm{Pb}, \mathrm{Sb}, \mathrm{Tl}$ and $\mathrm{V}$ in the sub-flow sewage sludge, nor for Sn in secondary liquid fuel (SLF) and solid recovered fuel (SRF), nor $\mathrm{Zn}$ in the sub-flows meat and bone meal (MBM) and SLF.

UK-specific trace metals concentration values in virgin materials (I11) and ARM (I21) could be found for all trace metals and sub-flows, except for Sn, for which no UK-specific data could be found for any of the sub-flows. Regarding the ARM, UK-specific data could be found for 
PFA, APCR and w-APCR for all trace metals, except Tl in the w-APCr. It was assumed that the concentration of Tl in APCR wasn't impacted by washing and thus the $\mathrm{Tl}$ concentration in w-APCR was set equal to the one in APCR. The quarry washings sub-flow represents a high fraction of the ARM mix (24\%) and no UK-specific data could be found. The concentrations of trace metals in the quarry washings sub-flow were assumed to be equal to the concentrations in the virgin raw material mix. The resulting $\mathrm{Cl}$ and trace metal concentrations in the alternative raw materials flow (I21) for the reference situation without co-processing of APCR can be seen in Table 2.

For material flows for which no UK-specific data could be found, for instance, millscale in the ARM, the mean of the concentration values of the other sub-flows of the same material flow (I21) was used. This assumption is similar to that made by Lederer et al.(2017), where trace metals flows were calculated for cement production in Austria in 2013.

Concentrations reported as below the analytical detection limit were set as the lowest detection limit for that element and material in the source. When no detection limit could be found, the concentration value was set to $0 \mathrm{mg} / \mathrm{kg}$.

Table 2: Element concentrations [mg/kg] in the flow alternative raw materials (I21) in S_Ref

\begin{tabular}{l|llll}
\hline & Minimum & Maximum & Median & $\#$ \\
\hline $\mathrm{Cl}$ & 32.6 & 1950 & 991 & 8 \\
$\mathrm{As}$ & 3.42 & 72.9 & 69.2 & 11 \\
$\mathrm{Cd}$ & 0.41 & 4.87 & 3.10 & 10 \\
$\mathrm{Co}$ & 4.52 & 80.2 & 15.5 & 10 \\
$\mathrm{Cr}$ & 46.3 & 129 & 66.5 & 9 \\
$\mathrm{Cu}$ & 46.7 & 319 & 83.1 & 12 \\
$\mathrm{Hg}$ & 0.01 & 0.41 & 0.32 & 7 \\
$\mathrm{Mn}$ & 134 & 1090 & 246 & 8 \\
$\mathrm{Ni}$ & 51.4 & 390 & 75.3 & 11 \\
$\mathrm{~Pb}$ & 2.66 & 68.3 & 35.3 & 10 \\
$\mathrm{Sb}$ & 1.30 & 216 & 3.46 & 8 \\
$\mathrm{Sn}$ & 933 & 1850 & 1390 & 2 \\
$\mathrm{Tl}$ & 10.2 & 10.2 & 10.2 & 3 \\
$\mathrm{~V}$ & 137 & 889 & 197 & 8 \\
$\mathrm{Zn}$ & 111 & 625 & 369 & 10 \\
\hline
\end{tabular}

\subsection{Scenarios}

Changes in the fate of trace metals linked to different proportions of APCR and w-APCR in the ARM were modelled using ten different scenarios (Table 3). It was assumed that the total raw inputs stayed constant over all scenarios. An increase in the proportion of ARM (I21) was therefore compensated with a decrease in virgin raw material input (Ill). The proportion of each sub-flow in the virgin raw material flow was kept constant in every scenario. However, clinker outputs slightly varied based on the rates of dust removal.

The first six scenarios model incremental increases in APCR and w-APCR co-processing. The proportion of APCR in the ARM mix increases from zero in the reference scenario (S_Ref) to $5 \%, 15 \%$ and $35 \%$ in scenarios $S \_5, S \_15$ and $S \_35$ respectively, while no w-APCR is coprocessed. In the next three scenarios, the impact of pre-treatment of APCR by washing is examined; the proportion of APCR is set to zero and that of w-APCR to $5 \%, 15 \%$ and $35 \%$ in 
scenarios S_w5, S_w15 and S_w35 respectively. The proportions modelled were the same as those used in APCR and w-APCR co-processing trials conducted at UCL within the abovementioned research project, to enable the results from modelling to be related to the coprocessing and leaching experiments.

The total amount of APCR produced in the UK in 2015 was $332 \mathrm{kt}$, based on the total flow of municipal solid waste incinerated in the UK in 2015 (Eurostat) and a value of 3.5\% APCR generation (Rani et al. 2008). Additionally, assuming incineration in the UK of the waste currently exported for incineration, the resulting amount of APCR produced would be $431 \mathrm{kt}$. Scenario S_UK shows the situation where all $332 \mathrm{kt}$ of APCR produced in the UK in 2015 is used for the manufacture of cement. Scenario S_Exp includes the APCR for the UK waste stream that is currently exported, i.e., $431 \mathrm{kt}$ total. The impact of APCR pre-treatment by washing is analysed in scenarios S_wUK and S_wEXP, similar to S_UK and S_Exp, but with W-APCR.

Table 3: Scenarios description.

\begin{tabular}{l|llll}
\hline & \multicolumn{5}{|c}{$\begin{array}{l}\text { Fraction of } \\
\text { DCKD back to } \\
\text { Scenario }\end{array}$} & Input concentrations & raw meal & APCR & W-APCR \\
\hline S_Ref & Median & 0 & 0 & 0 \\
S_5 & Median & 0 & $5 \%$ & 0 \\
S_15 & Median & 0 & $15 \%$ & 0 \\
S_35 & Median & 0 & $35 \%$ & 0 \\
S_w5 & Median & 0 & 0 & $5 \%$ \\
S_w15 & Median & 0 & 0 & $15 \%$ \\
S_w35 & Median & 0 & 0 & $35 \%$ \\
S_UK & Median & 0 & UK & 0 \\
S_Exp & Median & 0 & All & 0 \\
S_wUK & Median & 0 & 0 & UK \\
S_wExp & Median & 0 & 0 & All \\
\hline
\end{tabular}

\subsection{Sensitivity Analysis}

A sensitivity analysis was conducted to understand the robustness of the scenario analysis results. In a first step, the impact of variations in the toxic metal concentrations was examined by setting the input concentrations in all scenarios to their minimum, and then maximum values.

In a second step, the impact of the fraction of DCKD returned to the raw meal was examined. The value of this parameter is unknown for the reference state (2015) and the default value was set to zero. In the default parameterisation, it was assumed that all the CCKD was sent back to the raw meal and all the dust arising from direct operation was disposed off-site (hence the value of zero for the fraction of DCKD returned to the kiln). This assumption was motivated by the impact of compound operation on the dust composition. During compound operation, raw gas from the kiln flows through the raw mill, where some of the substances contained in the gas are retained within the raw meal (Achternbosch et al. 2005). For this reason, the $\mathrm{Cl}$ amount in DCKD is expected to be higher than that in CCKD. This phenomenon can also be observed with the help of the transfer coefficients of $\mathrm{Cl}$ during compound and direct operations. During compound operation, the fraction of $\mathrm{Cl}$ to raw meal is 0.997 . During direct operation, the fraction of $\mathrm{Cl}$ to DCKD is 0.993 . The difference between both coefficients accounts for the amount of $\mathrm{Cl}$ retained in the raw mill. The release of DCKD is a more efficient way to reduce $\mathrm{Cl}$ in the system than release of CCKD. For the sensitivity analysis, the fraction of DCKD sent 
back to the raw meal was increased from zero to $25 \%, 50 \%, 75 \%$ and $99 \%$ (to avoid dividing by zero, the value could not be $100 \%$ ).

\subsection{Assumptions and Limitations}

Before showing and discussing the results, it is important to note that the numerous assumptions made regarding the trace metals concentrations clearly influence the outcome of the model. UK-specific data could not be found for $\mathrm{Sn}$ in most of the flows and the fate of this trace metal could not be examined.

It was also assumed that the use of a certain quantity of APCR would produce the same high quality clinker as if the same quantity of virgin raw material had been used instead. In fact, other feed streams would have to be adjusted, because the concentrations of desirable elements in APCR (Bogush et al. 2015) differ from those in the other raw materials.

Also, the model was built with constant transfer coefficients, even though chlorine concentration is known to have an influence on metal volatilization (Saikia, Kato, and Kojima 2007). The modelling also didn't take into account the consequences of purging more gas with the bypass on the efficiency of the production process. Increasing amounts of raw gas being bypassed lead to less raw gas flowing through the preheater and therefore to an increased demand of heating via fuel combustion.

\section{Results}

\subsection{MFA}

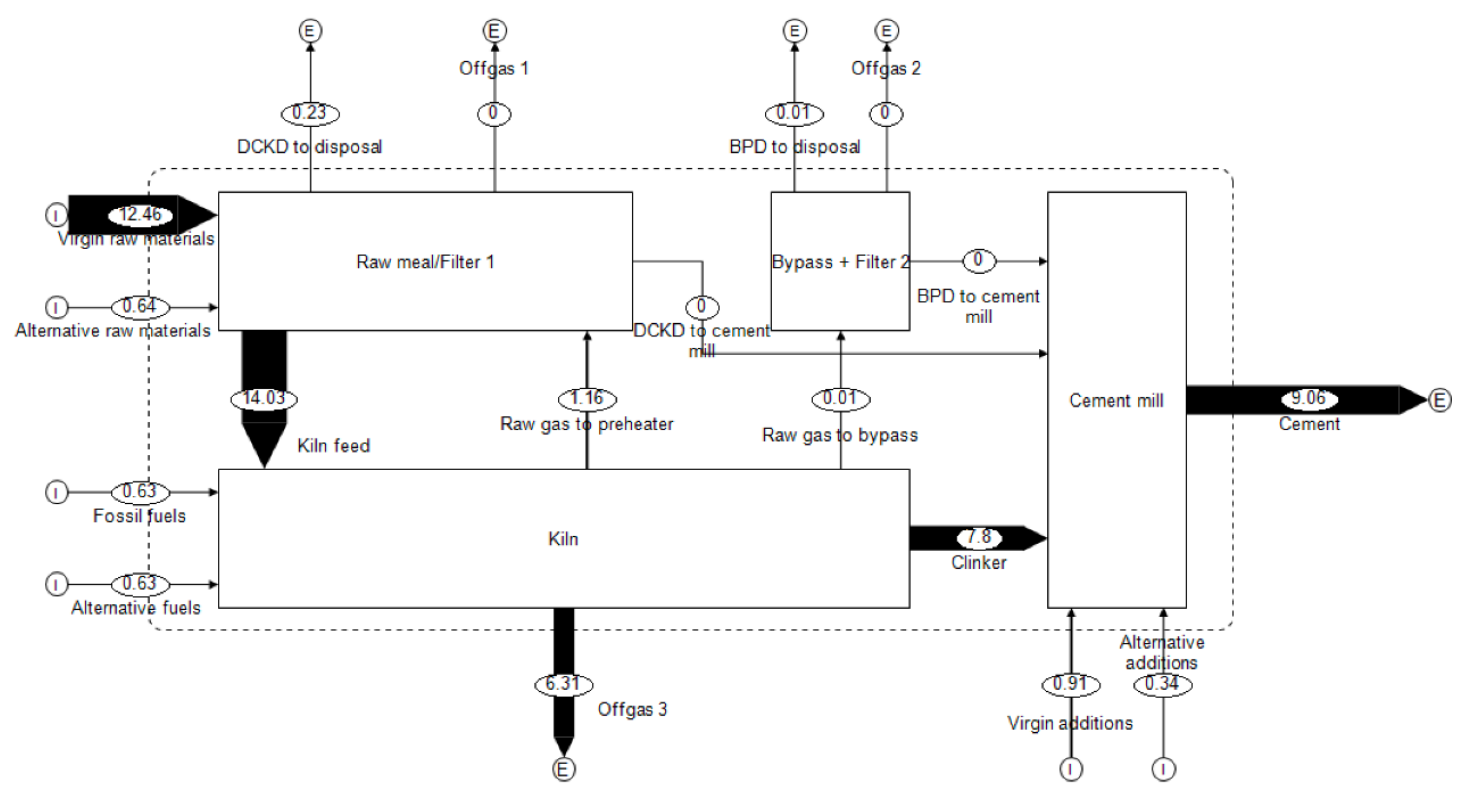

Figure 3: Resulting flows of material [Mt] for the year 2015 in the reference scenario (S_Ref).

Figure 3 shows the calculated flows of materials for the reference scenario S_ref in the year 2015. The values are expressed in Mt and mass balance inconsistencies are due to rounding of the values. 


\subsection{Scenario Analysis}

Table 4: Chlorine concentrations $[\mathrm{mg} / \mathrm{kg}]$ in clinker, BPD and DCKD in the different scenarios.

\begin{tabular}{lllll}
\hline & Fraction to bypass & Clinker & BPD & DCKD \\
\hline S_Ref & 0.01 & 469 & 59800 & 400 \\
S_5 & 0.11 & 11900 & 227000 & 600 \\
S_15 & 0.34 & 35700 & 227000 & 600 \\
S_35 & 0.81 & 87400 & 227000 & 600 \\
S_w5 & 0.01 & 801 & 103000 & 600 \\
S_w15 & 0.01 & 1430 & 190000 & 600 \\
S_w35 & 0.02 & 2630 & 227000 & 600 \\
S_UK & 0.06 & 6250 & 227000 & 600 \\
S_Exp & 0.07 & 7980 & 227000 & 600 \\
S_wUK & 0.01 & 642 & 81800 & 547 \\
S_wExp & 0.01 & 694 & 88300 & 591 \\
\hline
\end{tabular}

The chlorine concentrations in clinker, BPD and DCKD, as well as the fraction of raw gas purged via bypass in each scenario are shown in Table 4. Figure 4 shows the cement concentrations of $\mathrm{Cd}, \mathrm{Cr}$ and $\mathrm{Tl}$ in the developed scenarios. The results of the sensitivity analysis regarding the effect of variations in the input concentrations are expressed with the error bars. The concentration of $\mathrm{Cr}$ in cement increased more with the use of w-APCR than with APCR. On the other hand, the cement concentrations of Cd reached a maximum in S_35. The concentration of $\mathrm{Tl}$ in clinker showed a steady decrease and reached a minimum with the use of $35 \%$ APCR. The effects of the scenarios on the total trace metal loads leaving the system are presented in Figure 5.

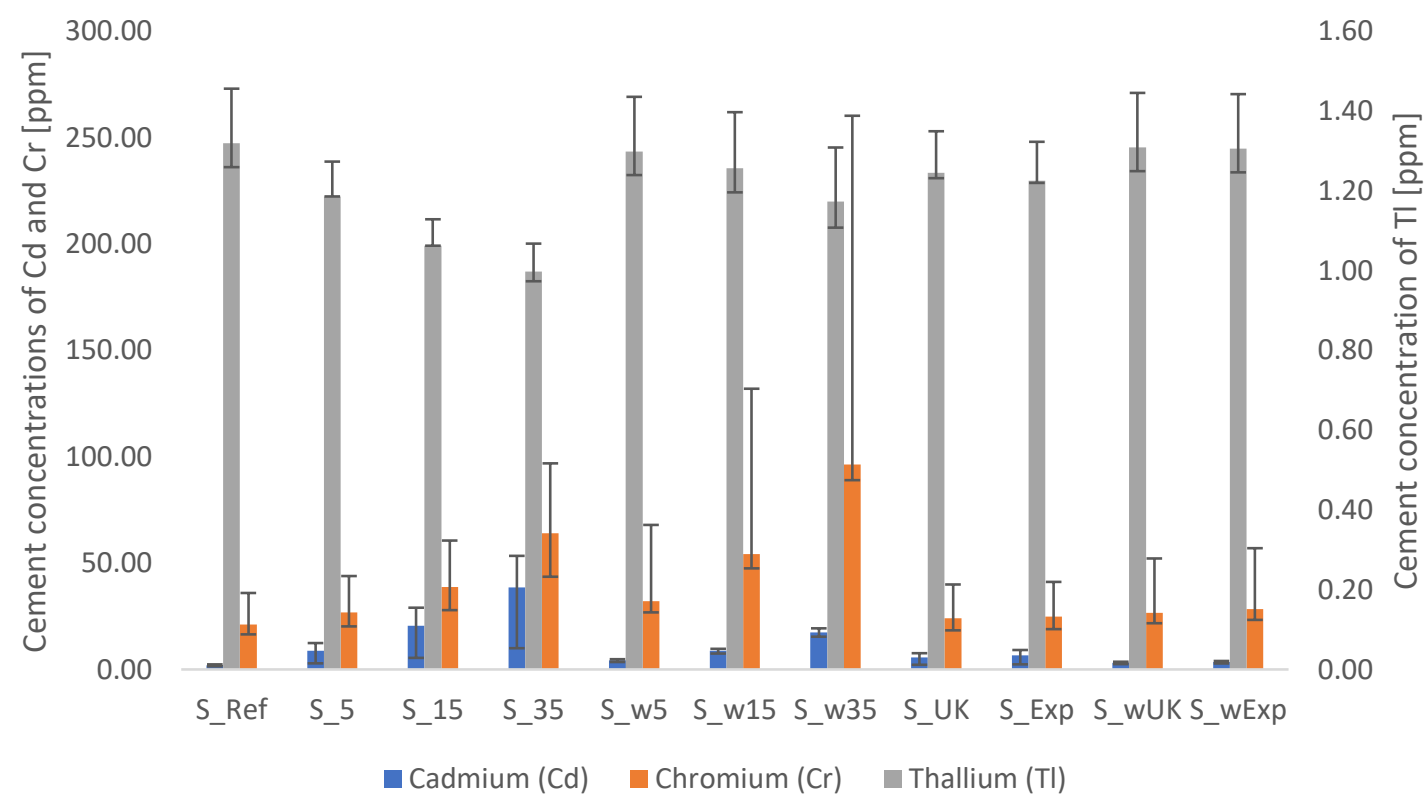

Figure 4: Influence of the scenarios and the sensitivity analysis regarding the minimum and maximum input concentrations on the cement concentrations of $\mathrm{Cd}, \mathrm{Cr}$ and $\mathrm{Tl}$. 


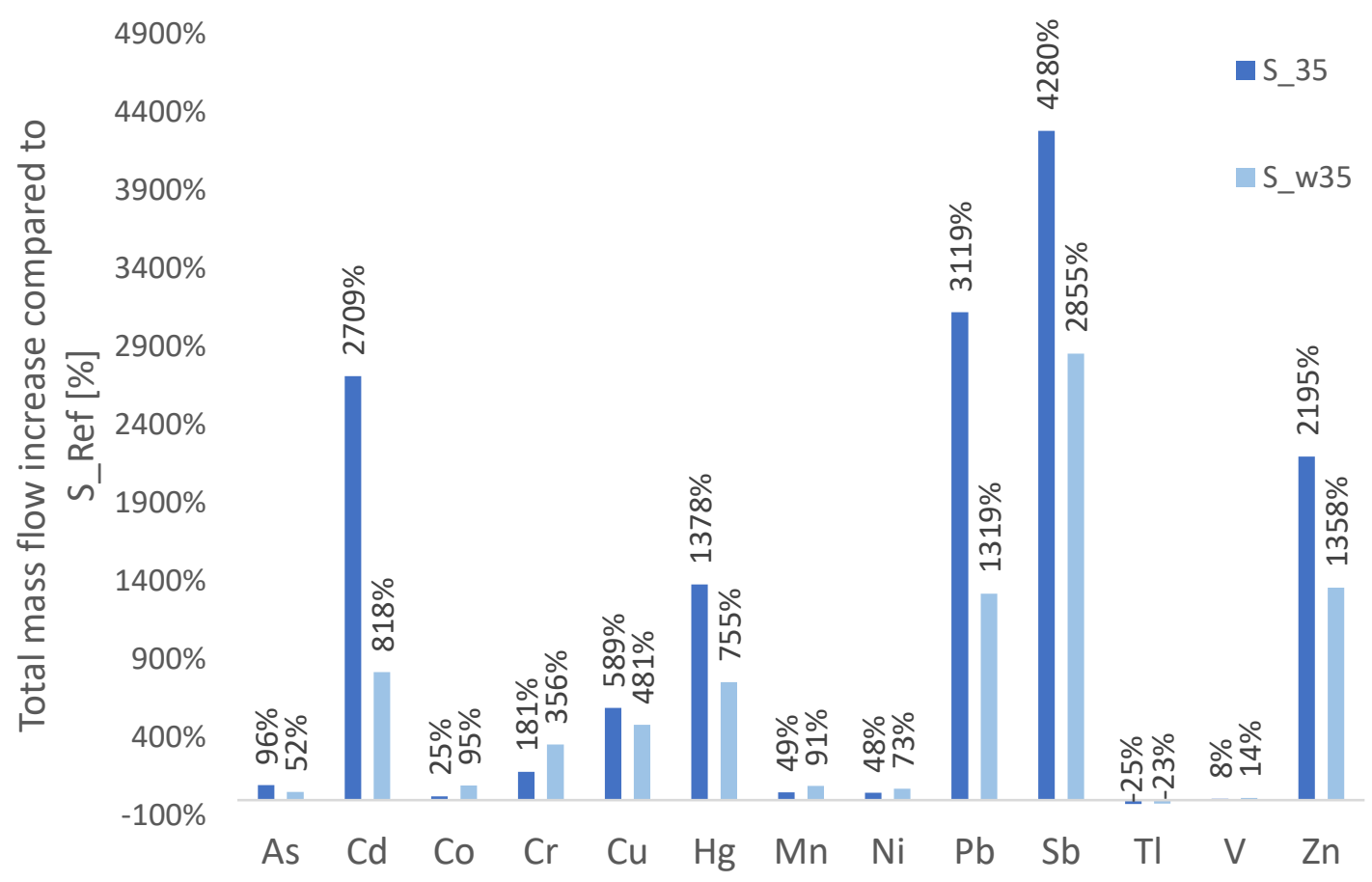

Figure 5: Total mass flow increase [\%] in S_35 and S_w35 compared to the reference scenario.

The results of the sensitivity analysis assessing the changes caused by increasing the fraction of DCKD returned to raw meal are shown in Table 5.

Table 5: Fraction to bypass, amounts of clinker, cement, concrete, BPD and DCKD [Mt] in the scenarios.

\begin{tabular}{l|lllll}
\hline Set & $\begin{array}{l}\text { Fraction to } \\
\text { bypass }\end{array}$ & $\begin{array}{l}\text { Clinker } \\
{[\mathrm{Mt}]}\end{array}$ & $\begin{array}{l}\text { Cement } \\
{[\mathrm{Mt}]}\end{array}$ & BPD [Mt] & $\begin{array}{l}\text { DCKD } \\
{[\mathrm{Mt}]}\end{array}$ \\
\hline SE_Ref_25 & 0.01 & 7.86 & 9.11 & 0.01 & 0.18 \\
SE_Ref_50 & 0.01 & 7.91 & 9.17 & 0.01 & 0.12 \\
SE_Ref_75 & 0.01 & 7.97 & 9.23 & 0.01 & 0.06 \\
SE_Ref_99 & 0.01 & 8.03 & 9.29 & 0.01 & 0.00 \\
\hline SE_35_25 & 0.81 & 7.11 & 8.36 & 0.90 & 0.03 \\
SE_35_50 & 0.81 & 7.12 & 8.38 & 0.90 & 0.02 \\
SE_35_75 & 0.81 & 7.13 & 8.39 & 0.90 & 0.01 \\
SE_35_99 & 0.81 & 7.14 & 8.40 & 0.90 & 0.00 \\
\hline SE_w35_25 & 0.02 & 7.84 & 9.10 & 0.02 & 0.17 \\
SE_w35_50 & 0.02 & 7.90 & 9.16 & 0.02 & 0.12 \\
SE_w35_75 & 0.02 & 7.96 & 9.22 & 0.02 & 0.06 \\
SE_w35_99 & 0.02 & 8.01 & 9.27 & 0.02 & 0.00 \\
\hline
\end{tabular}




\section{DISCUSSION}

\subsection{Scenario Analysis}

Figure 3 shows the overall material flows in the reference scenario S_Ref. Virgin raw materials represent the most important mass flow $(12.46 \mathrm{Mt})$. In this configuration, $0.59 \mathrm{t}$ of clinker and $0.69 \mathrm{t}$ are manufactured per $\mathrm{t}$ raw materials entering the process. The manufacture of $7.80 \mathrm{Mt}$ of clinker in 2015 was linked to the emissions of $6.31 \mathrm{Mt}$ of $\mathrm{CO}_{2}$. ARM accounted for $4.9 \%$ of the total raw material flow. This value increased up to 39.9\% in scenarios S_35 and S_w35.

According to Table 3, the use of APCR or w-APCR led to an increase of the raw gas that needed to be bypassed in all scenarios. In scenarios $S \_5$ to $S \_35$, this number increased from 0.11 to 0.81, compared to 0.01 and 0.02 in scenarios S_w5 and S_w35. The difference shows the impact that pre-washing could have on the kiln operation. It is in the interest of the operator to minimize the amount of raw gas leaving via bypass, as the efficiency of the process suffers from it. When more raw gas is bypassed, less is available for preheating and thus more fuel is needed. Perhaps even more importantly, the specific clinker production per raw material input is also reduced, as more dust is collected. In S_35, the efficiency of the process dropped to 0.54 $\mathrm{t}$ of clinker and $0.64 \mathrm{t}$ of cement produced per $\mathrm{t}$ of raw materials consumed.

Regarding the chlorine concentrations in BPD and DCKD, the maximum values of 227,000 and $600 \mathrm{mg} / \mathrm{kg}$, respectively, were reached in all scenarios using APCR (see Table 3). This, coupled with the large amounts of raw gas being bypassed and the difference between $\mathrm{Cl}$ concentrations in BPD and DCKD, indicates that plants without a bypass will encounter problems with maintaining equal amounts of $\mathrm{Cl}$ entering and leaving the production process when coprocessing APCR. The effects of such imbalances between $\mathrm{Cl}$ inputs and outputs will have to be further assessed to quantify the potential negative effects on the process.

Two main trends could be observed during the scenario analysis regarding the trace metals concentrations in clinker and cement. For Tl, the concentrations in the sub-flow APCR were lower than in the raw material flow (without APCR), leading to a concentration decrease in the raw material mix when APCR or w-APCR were added. The concentrations of the other trace metals increased in the raw material flow when APCR or w-APCR were added. The highest relative concentration increase in cement from $S \_5$ to $S \_35$ was more than 40 times for antimony, from 4.36 (S_Ref) to $195 \mathrm{mg} / \mathrm{kg}$ (S_35). It is important to note that during washing, some mass is lost and the remaining total amount of w-APCR is smaller than that of the APCR before washing; thus the concentrations of elements that weren't removed by washing are increased (Bogush, Stegemann, and Roy 2019). This mass loss was neglected, in assuming that the mass of w-APCR available in the UK was the same as that of APCR. The concentration increases in cement were therefore higher from S_Ref to S_w35 than to S_35 for Co, Cr, Mn and Ni.

The scenarios S_UK, S_Exp, S_wUK and S_wExp showed what could happen on a national level, if all the APCR produced in the UK $(332 \mathrm{kt})$ or all the APCR produced from UK wastes (431 kt) were used as raw material. These amounts would account for respectively 2.5 and $3.3 \%$ of the total materials used to produce cement. Regarding the amounts of APCR and w-APCR co-processed, these scenarios are situated between S_Ref and S_5, respectively S_w5. In those scenarios, the same trends could be observed and the trace metals concentrations in cement either decreased or increased with increasing use of APCR or w-APCR.

The cement concentration increase for all trace metals except $\mathrm{Tl}$ clearly shows the potential environmental impacts linked to co-processing APCR and w-APCR. However, they don't give 
any information about changes in total amounts of trace metals leaving the system and thus entering the environment. The values in Figure 5 indicate that the same trends as for the concentrations in cement have to be expected for the total amounts of trace metals entering and leaving the cement production process. Sb showed the highest increase, with a value of $4280 \%$ for $\mathrm{S} \_35$ compared to the reference situation. $\mathrm{Sb}$ is followed by $\mathrm{Pb}$ and $\mathrm{Cd}$, with values of respectively $3119 \%$ and $2709 \%$ regarding the total amounts. The use of $35 \%$ of APCR in the raw material mix could reduce the total mass flow of Tl to -25\%, compared to S_Ref. The high increase of $\mathrm{Sb}, \mathrm{Pb}$ and $\mathrm{Cd}$ flows and decrease of $\mathrm{Tl}$ flows are linked to the respective concentration differences of trace metal in the APCR and in the raw material mix without any APCR/w-APCR.

\subsection{Sensitivity Analysis}

The sensitivity analysis showed that the large variability of the $\mathrm{Cl}$ concentration ranges has an impact on the calculated fraction of raw gas sent to the bypass. With the minimum concentration values for the input materials, the fraction of raw gas purged via bypass dropped from 0.81 to 0.3 in scenario S3. When the maximum input concentrations were chosen, this number increased to 1, which implied that no raw gas could be sent to preheat the kiln feed and the efficiency of the process would be negatively impacted. The plant operation depends therefore on the $\mathrm{Cl}$ concentrations. In addition to the amount of raw gas that needed to be bypassed, the changes in input concentrations also had an influence on the trace metals trends that could be observed in the scenario analysis. Figure 4 shows that depending on the chosen input data, the observed trends in cement concentration would vary from those in the reference situation. On top of that, the total mass flows of trace metals are also impacted by the concentrations of the inputs. The total amount of Sb leaving the system could be underestimated by $653 \%$ in the reference scenario and that of $\mathrm{Pb}$ overestimated by $96 \%$ in S_35 compared to S_Ref, where median concentrations were used (tables 5, 6 and 7 in S5). The collection of more UK-specific data would help reduce the uncertainties in these results. The variation of the fraction of DCKD returned to the raw meal doesn't have any impact on the total amounts of trace metals leaving the system. However, the efficiency of the process is impacted, as more material is available for the production of clinker when more DCKD is returned to the raw meal. The production of cement therefore increased from 7.80 to $8.03 \mathrm{Mt}$ in the reference scenario, when all the DCKD was returned to the raw meal.

\section{CONCLUSIONS}

Co-processing of ARM can reduce virgin extraction and limit waste to landfill but is likely to raise the level of contamination in cement. This study has shown that, compared to current practices, the use of APCR for co-processing would significantly raise the concentration of several trace metals in cement. The pre-washing of APCR clearly reduces the inputs of $\mathrm{Cl}$ in the system and reduces the amount of raw gas that needs to be bypassed. However, the loss of material during washing can lead to an increase of the trace metals concentrations in w-APCR compared to APCR and therefore to higher trace metals concentrations in clinker and cement (Co, Cr, Mn, Ni and V). In our modelling, a share of APCR of $35 \%$ of the total raw material mix leads to a situation where $81 \%$ of the raw gas needs to be purged via the bypass, which is detrimental to the efficiency of the plant, as heat and material are lost during the process. Further work would be necessary to quantify these losses. Full usage of APCR from the UK, or from all UK waste that is sent to combustion domestically or abroad, would increase the concentration of most trace metals in clinker and cement. Further research and more UKspecific data is needed to obtain more robust results from the model and to estimate the impact of APCR and w-APCR co-processing on the environment. 


\section{ACKNOWLEDGEMENTS}

This work was funded in part by the UK Engineering and Physical Sciences Research Council (Grant EP/M00337X/1). The authors would like to thank Paul Stevens from the Environment Agency; Rebecca Hooper and Colum McCague from the Mineral Products Association, Iain Walpole from Hanson UK and Stefanie Hellweg from the ETH in Zürich for helpful discussions.

\section{REFERENCES}

Achternbosch, Matthias et al. 2005. "Impact of the Use of Waste on Trace Element Concentrations in Cement and Concrete." Waste Management and Research 23(4): 328-37.

Amec Foster Wheeler Environment. 2015. Rapid Evidence Assessment: Cement Kiln Dust and By-Pass Dust from Cement Kilns. Department of Environment, Food and Rural Affairs.

Boesch, Michael E, Carl Vadenbo, and Stefanie Hellweg. "LCA4Waste Good Practice Guidelines."

Bogush, Anna, Julia A. Stegemann, and Amitava Roy. 2019. "Changes in Composition and Lead Speciation Due to Water Washing of Air Pollution Control Residue from Municipal Waste Incineration.” Journal of Hazardous Materials 361(February 2018): 187-99. https://doi.org/10.1016/j.jhazmat.2018.08.051.

Bogush, Anna, Julia A. Stegemann, Ian Wood, and Amitava Roy. 2015. "Element Composition and Mineralogical Characterisation of Air Pollution Control Residue from UK Energy-from-Waste Facilities." Waste Management 36: 119-29. http://dx.doi.org/10.1016/j.wasman.2014.11.017.

Dr. Graf AG. 1998. Regelungen Über Die Abfallentsorgung in Zementwerken. ed. Bundesamt für Umwelt Wald und Landschaft (BUWAL).

Lanzerstorfer, Christof. 2016. "Residue from the Chloride Bypass De-Dusting of Cement Kilns: Reduction of the Chloride Content by Air Classification for Improved Utilisation." Process Safety and Environmental Protection 104: 444-50.

http://dx.doi.org/10.1016/j.psep.2016.06.010.

Saikia, Nabajyoti, Shigeru Kato, and Toshinori Kojima. 2007. "Production of Cement Clinkers from Municipal Solid Waste Incineration ( MSWI ) Fly Ash.” 27: 1178-89.

Stegemann, J.A. 2014. “The Potential Role of Energy-from-Waste Air Pollution Control Residues in the Industrial Ecology of Cement." Journal of Sustainable Cement-Based Materials 3(2): 111-27. 


\section{SUPPORTING INFORMATION}

S1

Table 1: Transfer coefficients (Neosys AG, 2004)

\begin{tabular}{|c|c|c|c|c|c|c|c|c|}
\hline & \multicolumn{4}{|c|}{ Raw mill \& Filter } & \multicolumn{2}{|c|}{ Kiln } & \multicolumn{2}{|c|}{ Bypass } \\
\hline & \multicolumn{2}{|c|}{$\mathrm{CO}$} & \multicolumn{2}{|c|}{ DO } & \multirow[b]{2}{*}{ Raw gas } & \multirow[b]{2}{*}{ Clinker } & \multirow[b]{2}{*}{ BPD } & \multirow[b]{2}{*}{ Raw gas } \\
\hline & $\begin{array}{l}\text { Raw } \\
\text { meal }\end{array}$ & $\begin{array}{c}\text { Raw } \\
\text { gas }\end{array}$ & DCKD & $\begin{array}{c}\text { Raw } \\
\text { gas }\end{array}$ & & & & \\
\hline Material & 0.99997 & 0.00003 & 0.99980 & 0.00020 & 0.07700 & 0.92300 & 0.99980 & 0.00020 \\
\hline Cl & 0.99700 & 0.00300 & 0.99300 & 0.00700 & 0.25000 & 0.75000 & 0.99300 & 0.00700 \\
\hline As & 0.99960 & 0.00040 & 0.99800 & 0.00200 & 0.09000 & 0.91000 & 0.99800 & 0.00200 \\
\hline Cd & 0.97000 & 0.03000 & 0.91000 & 0.09000 & 0.50000 & 0.50000 & 0.91000 & 0.09000 \\
\hline Co & 0.99930 & 0.00070 & 0.99800 & 0.00200 & 0.03000 & 0.97000 & 0.99800 & 0.00200 \\
\hline $\mathrm{Cr}$ & 0.99990 & 0.00010 & 0.99900 & 0.00100 & 0.00300 & 0.99700 & 0.99900 & 0.00100 \\
\hline $\mathbf{C u}$ & 0.99800 & 0.00200 & 0.99800 & 0.00200 & 0.02000 & 0.98000 & 0.99800 & 0.00200 \\
\hline Hg & 0.84000 & 0.16000 & 0.80000 & 0.20000 & 0.99800 & 0.00200 & 0.80000 & 0.20000 \\
\hline Mn & 0.99907 & 0.00093 & 0.99847 & 0.00153 & 0.02667 & 0.97333 & 0.99847 & 0.00153 \\
\hline $\mathbf{N i}$ & 0.99990 & 0.00010 & 0.99940 & 0.00060 & 0.03000 & 0.97000 & 0.99940 & 0.00060 \\
\hline $\mathbf{P b}$ & 0.97100 & 0.02900 & 0.95000 & 0.05000 & 0.50000 & 0.50000 & 0.95000 & 0.05000 \\
\hline Sb & 0.99960 & 0.00040 & 0.99800 & 0.00200 & 0.09000 & 0.91000 & 0.99800 & 0.00200 \\
\hline Sn & 0.99960 & 0.00040 & 0.99700 & 0.00300 & 0.50000 & 0.50000 & 0.99700 & 0.00300 \\
\hline Tl & 0.99990 & 0.00010 & 0.99990 & 0.00010 & 0.98700 & 0.01300 & 0.99990 & 0.00010 \\
\hline V & 0.99907 & 0.00093 & 0.99847 & 0.00153 & 0.02667 & 0.97333 & 0.99847 & 0.00153 \\
\hline Zn & 0.99800 & 0.00200 & 0.97500 & 0.02500 & 0.01500 & 0.98500 & 0.97500 & 0.02500 \\
\hline
\end{tabular}


Table 2: Coefficients used in the calculations of material and substance flows

\begin{tabular}{|c|l|l|l|}
\hline Coefficient & \multicolumn{1}{|c|}{ Value } & \multicolumn{1}{|c|}{ Description } & \multicolumn{1}{|c|}{ Source } \\
\hline $\mathrm{k}_{1}$ & $2.38 \mathrm{t} / \mathrm{m}^{3}$ & $\begin{array}{l}\text { Density of ready- } \\
\text { mixed concrete }\end{array}$ & MPA \\
\hline $\mathrm{k}_{2}$ & $0.26 \mathrm{t}$ cement $/ \mathrm{m}^{3}$ concrete & $\begin{array}{l}\text { Amount of } \\
\text { cement in ready- } \\
\text { mixed concrete }\end{array}$ & ERMCO \\
\hline $\mathrm{k}_{3}$ & $0.16 \mathrm{t}$ cementitious/t concrete & $\begin{array}{l}\text { Amount of } \\
\text { cementitious } \\
\text { material in } \\
\text { precast concrete }\end{array}$ & MPA \\
\hline $\mathrm{k}_{4}$ & 0.8 & $\begin{array}{l}\text { Fraction of the } \\
\text { time, during } \\
\text { which CO is run }\end{array}$ & MPA, personal \\
comm.
\end{tabular}


Table 3: Calculations and data source for the material flows.

\begin{tabular}{|c|c|c|}
\hline Input flows & 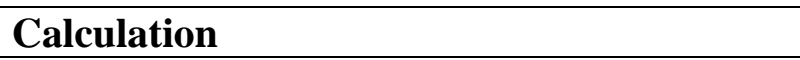 & Source \\
\hline I11 & None & \\
\hline $\mathrm{I} 21$ & None & $\begin{array}{l}\text { MPA, personal } \\
\text { comm. DC }\end{array}$ \\
\hline I12 & None & MPA, sankey \\
\hline $\mathrm{I} 22$ & None & MPA, sankey \\
\hline \multicolumn{3}{|l|}{ I14 } \\
\hline $\mathrm{I} 24$ & None & $\begin{array}{l}\text { MPA, personal } \\
\text { comm. DC }\end{array}$ \\
\hline $\mathrm{I} 15$ & $=F 45 \cdot \frac{k_{1}}{k_{2}} \cdot k_{3}-F 45$ & See S2 \\
\hline $\mathrm{I} 25$ & $=F 45 \cdot \frac{k_{1}}{k_{2}}-F 45-I 15$ & See S2 \\
\hline \multicolumn{3}{|l|}{$\begin{array}{l}\text { Process } \\
\text { flows }\end{array}$} \\
\hline F12 & $\begin{array}{l}=(I 11+I 21) \cdot T C_{C O \rightarrow \text { raw meal }} \\
+F 21 \cdot k_{4} \cdot T C_{C O \rightarrow \text { raw meal }} \\
+\left(F 21 \cdot\left(1-k_{4}\right) \cdot T C_{D O \rightarrow D C K D}-F 14\right) \cdot k_{5}\end{array}$ & See S2 \\
\hline F21 & $=(I 12+I 22+F 12) \cdot T C_{\text {Kiln } \rightarrow \text { raw gas }}-F 23$ & See S2 \\
\hline F23 & $=(I 12+I 22+F 12) \cdot T C_{\text {Kiln } \rightarrow \text { raw gas }} \cdot k_{6}$ & See S2 \\
\hline F14 & None & $\begin{array}{l}\text { MPA, person. } \\
\text { communications }\end{array}$ \\
\hline F24 & None & $\begin{array}{l}\text { MPA, annual } \\
\text { cementitious }\end{array}$ \\
\hline F34 & None & $\begin{array}{l}\text { MPA, person. } \\
\text { communications }\end{array}$ \\
\hline \multicolumn{3}{|l|}{ Outputs } \\
\hline O11 & $\begin{array}{c}=\left(F 21 \cdot\left(1-k_{4}\right) \cdot T C_{D O \rightarrow D C K D}-F 14\right) \\
\cdot\left(1-k_{5}\right)\end{array}$ & See S2 \\
\hline $\mathrm{O} 12$ & $\begin{array}{c}=(I 11+I 21) \cdot T C_{C O \rightarrow \text { offgas }} \\
+F 21\left(k_{4} \cdot T C_{C O \rightarrow \text { offgas }}+\left(1-k_{4}\right)\right. \\
\left.\cdot T C_{D O \rightarrow \text { offgas }}\right)\end{array}$ & See S2 \\
\hline $\mathrm{O} 31$ & $=F 23 \cdot T C_{B P \rightarrow B P D}-F 34$ & See S2 \\
\hline $\mathrm{O} 32$ & $=F 23 \cdot T C_{B P \rightarrow o f f g a s}$ & See S2 \\
\hline O51 & $=I 15+I 25+F 45$ & \\
\hline
\end{tabular}


Table 4: Calculations and data source for the $\mathrm{Cl}$ concentrations.

\begin{tabular}{|c|c|c|}
\hline Inputs & Calculation & Source \\
\hline $\mathrm{C}_{\mathrm{Cl}, \mathrm{I} 11}$ & None & Trial reports \\
\hline $\mathrm{C}_{\mathrm{Cl}, \mathrm{I21}}$ & None & Trial reports \\
\hline $\mathrm{C}_{\mathrm{Cl}, \mathrm{I} 12}$ & None & Trial reports \\
\hline $\mathrm{C}_{\mathrm{Cl}, \mathrm{I} 22}$ & None & Trial reports \\
\hline \multicolumn{3}{|l|}{$\begin{array}{l}\text { Process } \\
\text { flows }\end{array}$} \\
\hline $\mathrm{C}_{\mathrm{Cl}, \mathrm{F} 12}$ & $\begin{array}{l}=\left[\left(I 11 \cdot C_{C l, I 11}+I 21 \cdot C_{C l, I 21}\right) \cdot T C_{C l, C O \rightarrow \text { raw meal }}\right. \\
+F 21 \cdot C_{C l, F 21} \cdot k_{4} \cdot T C_{C l, C O \rightarrow \text { raw meal }} \\
\left.+C_{C l, F 21} \cdot\left(F 21 \cdot\left(1-k_{4}\right) \cdot T C_{D O \rightarrow D C K D}-F 14\right) \cdot k_{5}\right] \cdot \frac{1}{F 12}\end{array}$ & See S2 \\
\hline $\mathrm{C}_{\mathrm{Cl} \text {, Kiln }}$ & $=\frac{\left[\left(I 12 \cdot C_{C l, I 12}+I 22 \cdot C_{C l, I 22}\right)+F 12 \cdot C_{C l, F 12}\right]}{I 12+I 22+F 12}$ & See S2 \\
\hline $\mathrm{C}_{\mathrm{Cl}, \mathrm{F} 12}$ & $=C_{C l, O 11} \cdot \frac{T C_{D O \rightarrow D C K D}}{T C_{C l, D O \rightarrow D C K D}}$ & See S2 \\
\hline $\mathrm{C}_{\mathrm{Cl}, \mathrm{F} 14}$ & None & Trial reports \\
\hline $\mathrm{C}_{\mathrm{Cl}, \mathrm{F} 23}$ & $=\frac{(031+F 34) \cdot C_{C l, 031}}{F 23 \cdot T C_{C l, B P \rightarrow B P D}}$ & See S2 \\
\hline $\mathrm{C}_{\mathrm{Cl}, \mathrm{F} 34}$ & None & Trial reports \\
\hline $\mathrm{C}_{\mathrm{Cl}, \mathrm{F} 23}$ & $=\frac{(031+F 34) \cdot C_{C l, O 31}}{F 23 \cdot T C_{C l, B P \rightarrow B P D}}$ & See S2 \\
\hline $\mathrm{C}_{\mathrm{Cl}, \mathrm{F} 24}$ & $=\frac{C_{C l, k i l n} \cdot(I 12+I 22+F 12) \cdot T C_{C l, k i l n \rightarrow c l i n k e r}}{F 24}$ & See S2 \\
\hline \multicolumn{3}{|l|}{ Outputs } \\
\hline $\mathrm{C}_{\mathrm{Cl}, \mathrm{O} 11}$ & None & Trial \\
\hline $\mathrm{C}_{\mathrm{Cl}, \mathrm{O} 12}$ & $\begin{array}{l}=\left[\left(I 11 \cdot C_{C l, I 11}+I 21 \cdot C_{C l, I 21}\right) \cdot T C_{C l, C O \rightarrow \text { offgas }}\right. \\
+F 21 \cdot C_{C l, F 21} \cdot\left(k_{4} \cdot T C_{C l, C O \rightarrow \text { offgas }}+\left(1-k_{4}\right)\right. \\
\left.\left.\cdot T C_{C l, D O \rightarrow \text { offgas }}\right)\right] \\
\cdot \frac{1}{O 21}\end{array}$ & See S2 \\
\hline $\mathrm{C}_{\mathrm{Cl}, \mathrm{O} 31}$ & None & Trial \\
\hline $\mathrm{C}_{\mathrm{Cl}, \mathrm{O} 22}$ & $=\frac{F 23 \cdot C_{C l, F 23} \cdot T C_{C l, B P \rightarrow \text { offgas }}}{032}$ & See S2 \\
\hline
\end{tabular}


Table 5: Flows of trace metals [t] via cement during the sensitivity analysis (minimum input concentrations).

\begin{tabular}{|c|c|c|c|c|c|c|c|c|c|c|c|c|c|}
\hline Set & As & Cd & Co & $\mathrm{Cr}$ & $\mathbf{C u}$ & $\mathrm{Hg}$ & Mn & $\mathbf{N i}$ & $\mathbf{P b}$ & $\mathbf{S b}$ & TI & $\mathbf{V}$ & Zn \\
\hline SE_Ref & 33.5 & 13.4 & 129. & 149. & 223. & 0.0 & 2751. & 201.2 & 95.9 & 28.1 & 11.4 & 339. & 749.1 \\
\hline$\overline{\min }$ & 4 & 8 & 10 & 22 & 30 & 8 & 56 & 6 & 7 & 3 & 0 & 52 & 8 \\
\hline & 39.6 & 25.8 & 129. & 182. & 424. & 0.1 & 2798. & 208.0 & 99.3 & 135. & 10.7 & 339. & 2418. \\
\hline SE_5min & 8 & 6 & 37 & 64 & 23 & 3 & 21 & 0 & 8 & 74 & 8 & 67 & 36 \\
\hline SE_15mi & 51.7 & 48.6 & 129. & 249. & 825. & 0.2 & 2890. & 221.3 & 104. & 348. & & 339. & 5751. \\
\hline $\mathbf{n}$ & 9 & 1 & 85 & 46 & 19 & 1 & 13 & 8 & 64 & 80 & 9. & 86 & 34 \\
\hline SE_35mi & 75.5 & 87.7 & 130. & 383. & 1623 & 0.3 & 3072 . & 247.9 & 113. & 766. & 055 & 340. & 12396 \\
\hline $\mathbf{n}$ & 3 & 3 & 80 & 02 & .70 & 1 & 77 & 4 & 54 & 42 & & 20 & .16 \\
\hline SE_w5m & 39.1 & 31.5 & 147. & 242. & 417. & 0.1 & 3144. & 226.3 & 378. & 35.9 & 11.2 & 347. & 3071. \\
\hline in & 3 & 7 & 68 & 87 & 93 & 1 & 98 & 7 & 67 & 2 & 2 & 02 & 06 \\
\hline SE_w15 & 50.3 & 67.6 & 184. & 430. & 807. & 0.1 & 3931. & 276.5 & 942. & 51.4 & 10.8 & 362. & 7714. \\
\hline $\min$ & 0 & 6 & 83 & 17 & 16 & 7 & 62 & 9 & 58 & 7 & 3 & 00 & 58 \\
\hline SE_w35 & 72.6 & 139. & 259. & 804. & 1585 & 0.2 & 5504. & 376.9 & 2060 & 82.5 & 10.0 & 391. & 16999 \\
\hline $\min$ & 1 & 15 & 11 & 75 & .42 & 8 & 19 & 7 & .02 & 4 & 2 & 94 & .96 \\
\hline SE_UK & 36.6 & 19.8 & 129. & 166. & 325. & 0.1 & 2775 . & 204.7 & 97.9 & 82.8 & 11.1 & 339. & 1596. \\
\hline $\min$ & 7 & 8 & 25 & 18 & 30 & 1 & 51 & 0 & 9 & 3 & 4 & 63 & 37 \\
\hline SE_Exp & 37.6 & 21.7 & 129. & 171. & 355. & 0.1 & 2782. & 205.7 & 98.4 & 99.0 & 11.0 & 339. & 1848. \\
\hline $\min$ & 0 & 3 & 29 & 22 & 60 & 2 & 46 & 1 & 2 & 5 & 3 & 64 & 11 \\
\hline SE_wUK & 36.3 & 22.6 & 138. & 196. & 322. & 0.1 & 2951. & 214.0 & 239. & 32.0 & 11.3 & 343. & 1927. \\
\hline$\overline{\min }$ & 8 & 6 & 53 & 73 & 06 & 0 & 18 & 0 & 41 & 8 & 1 & 33 & 29 \\
\hline SE_wEx & 37.2 & 25.3 & 141. & 210. & 351. & 0.1 & 3010 . & 217.7 & 282. & 33.2 & 11.2 & 344. & 2277. \\
\hline pmin & 2 & 9 & 33 & 86 & 41 & 0 & 52 & 9 & 05 & 6 & 9 & 46 & 52 \\
\hline
\end{tabular}

Table 6 : Flows of trace metals [t] via cement during the sensitivity analysis (maximum input concentrations).

\begin{tabular}{l|lllllllllllll} 
Set & As & $\mathbf{C d}$ & $\mathbf{C o}$ & $\mathbf{C r}$ & $\mathbf{C u}$ & $\mathbf{H g}$ & $\mathbf{M n}$ & $\mathbf{N i}$ & $\mathbf{P b}$ & $\mathbf{S b}$ & $\mathbf{T l}$ & $\mathbf{V}$ & $\mathbf{Z n}$ \\
\hline SE_Ref & 119. & 21.5 & 265. & 325.4 & 841.6 & 0.3 & 4160. & 670. & 253.2 & 297.0 & 13.1 & 1276.1 & 1966.1 \\
max & 72 & 7 & 37 & 2 & 8 & 5 & 64 & 33 & 2 & 8 & 8 & 8 & 2 \\
SE_5ma & 141. & 110 & 273. & 392.4 & 1205. & 0.3 & 4513. & 698. & 1196. & 617.5 & 11.3 & 1289.1 & 6678.0 \\
$\mathbf{x}$ & 51 & 91 & 58 & 8 & 66 & 9 & 84 & 19 & 33 & 5 & 8 & 1 & 3 \\
SE_15m & 183. & 252. & 289. & 526.4 & 1928. & 0.4 & 5212. & 753. & 2687. & 1238. & 9.81 & 1314.3 & 16054. \\
ax & 61 & 22 & 72 & 4 & 52 & 2 & 42 & 14 & 35 & 21 & & 8 & 33 \\
SE_35m & 262. & 437. & 321. & 793.7 & 3353. & 0.4 & 6580. & 860. & 4641. & 2400. & 8.75 & 1363.4 & 34607. \\
ax & 26 & 50 & 16 & 7 & 49 & 6 & 94 & 34 & 10 & 05 & & 77 \\
SE_w5 & 127. & 43.6 & 285. & 615.1 & 1103. & 0.3 & 4589. & 713. & 606.5 & 494.2 & 13.0 & 1301.8 & 4732.5 \\
max & 78 & 4 & 99 & 1 & 65 & 8 & 56 & 43 & 4 & 1 & 0 & 9 & 1 \\
SE_w15 & 143. & 87.7 & 327. & 1194. & 1627. & 0.4 & 5447. & 799. & 1312. & 888.4 & 12.6 & 1353.3 & 10265. \\
max & 91 & 3 & 24 & 47 & 57 & 4 & 44 & 65 & 24 & 0 & 5 & 4 & 16 \\
SE_w35 & 176. & 174. & 409. & 2353. & 2674. & 0.5 & 7161. & 971. & 2704. & 1675. & 11.8 & 1456.0 & 21327. \\
max & 05 & 67 & 65 & 14 & 98 & 5 & 74 & 90 & 40 & 41 & 3 & 4 & 53 \\
SE_UK & 130. & 68.7 & 269. & 359.4 & 1026. & 0.3 & 4340. & 684. & 751.5 & 460.5 & 12.1 & 1282.8 & 4358.9 \\
max & 86 & 7 & 56 & 5 & 60 & 7 & 36 & 53 & 3 & 7 & 4 & 1 & 1
\end{tabular}




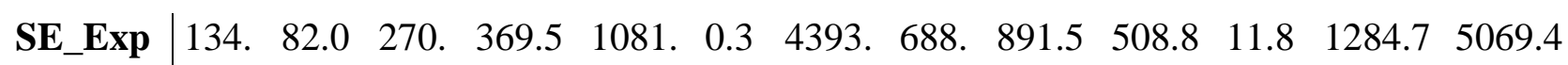
\begin{tabular}{l|lllllllllllll}
$\max$ & 13 & 4 & 79 & 7 & 47 & 8 & 54 & 72 & 4 & 1 & 8 & 4 & 5
\end{tabular}

$\begin{array}{llllllllllllll}\text { SE_wU } & 123 . & 32.7 & 275 . & 472.4 & 974.6 & 0.3 & 4378 . & 692 . & 432.5 & 397.1 & 13.0 & 1289.2 & 3369.7\end{array}$ \begin{tabular}{l|lllllllllllll} 
Kmax & 81 & 7 & 83 & 1 & 0 & 7 & 27 & 20 & 4 & 0 & 9 & 2 & 8
\end{tabular}

\begin{tabular}{l|lllllllllllll} 
SE_wEx & 125. & 36.1 & 278. & 516.1 & 1014 & 0.3 & 4442. & 698. & 485.8 & 426.8 & 13.0 & 1293.1 & 3787.0
\end{tabular} \begin{tabular}{l|lllllllllllll} 
pmax & 03 & 0 & 94 & 0 & 12 & 7 & 97 & 70 & 2 & 4 & 6 & 0 & 6 \\
\hline
\end{tabular} 
Table 7: Flows of trace metals [ $\mathrm{t}]$ via cement during the scenario analysis.

\begin{tabular}{|c|c|c|c|c|c|c|c|c|c|c|c|c|c|}
\hline $\begin{array}{c}\text { Ceme } \\
\text { nt }\end{array}$ & As & Cd & Co & $\mathrm{Cr}$ & $\mathrm{Cu}$ & Hg & Mn & $\mathbf{N i}$ & $\mathbf{P b}$ & Sb & TI & V & Zn \\
\hline S_Ref & $\begin{array}{c}107 . \\
81\end{array}$ & 17.68 & $\begin{array}{c}146.6 \\
7\end{array}$ & $\begin{array}{c}190.9 \\
7\end{array}$ & $\begin{array}{c}347.1 \\
9\end{array}$ & $\begin{array}{c}0.2 \\
7\end{array}$ & $\begin{array}{c}2929.1 \\
1\end{array}$ & $\begin{array}{c}257.5 \\
4\end{array}$ & $\begin{array}{c}154.0 \\
6\end{array}$ & 39.47 & 11.94 & $\begin{array}{c}434.1 \\
1\end{array}$ & $\begin{array}{c}1225 \\
32\end{array}$ \\
\hline S_5 & $\begin{array}{c}121 . \\
75\end{array}$ & 79.25 & $\begin{array}{c}151.4 \\
8\end{array}$ & $\begin{array}{c}240.2 \\
5\end{array}$ & $\begin{array}{c}638.0 \\
4\end{array}$ & $\begin{array}{c}0.3 \\
1\end{array}$ & $\begin{array}{c}3129.8 \\
4\end{array}$ & $\begin{array}{c}274.7 \\
0\end{array}$ & $\begin{array}{c}767.9 \\
4\end{array}$ & $\begin{array}{c}278.1 \\
6\end{array}$ & 10.63 & $\begin{array}{c}438.1 \\
5\end{array}$ & $\begin{array}{c}5057 . \\
44\end{array}$ \\
\hline S_15 & $\begin{array}{c}148 . \\
78\end{array}$ & $\begin{array}{c}180.5 \\
3\end{array}$ & $\begin{array}{c}160.9 \\
2\end{array}$ & $\begin{array}{c}338.6 \\
9\end{array}$ & $\begin{array}{c}1216 \\
40\end{array}$ & $\begin{array}{c}0.3 \\
6\end{array}$ & $\begin{array}{c}3526.5 \\
4\end{array}$ & $\begin{array}{c}308.5 \\
8\end{array}$ & $\begin{array}{c}1777 . \\
61\end{array}$ & $\begin{array}{c}743.3 \\
1\end{array}$ & 9.31 & $\begin{array}{c}445.9 \\
5\end{array}$ & $\begin{array}{c}12690 \\
.00\end{array}$ \\
\hline S_35 & $\begin{array}{c}199 . \\
93\end{array}$ & $\begin{array}{c}322.5 \\
6\end{array}$ & $\begin{array}{c}179.4 \\
0\end{array}$ & $\begin{array}{c}535.2 \\
2\end{array}$ & $\begin{array}{c}2359 \\
85\end{array}$ & $\begin{array}{c}0.4 \\
1\end{array}$ & $\begin{array}{c}4306.7 \\
1\end{array}$ & $\begin{array}{c}375.0 \\
8\end{array}$ & $\begin{array}{c}3193 . \\
06\end{array}$ & $\begin{array}{c}1625 \\
32\end{array}$ & 8.34 & $\begin{array}{c}461.1 \\
5\end{array}$ & $\begin{array}{c}27824 \\
.79\end{array}$ \\
\hline S_w5 & $\begin{array}{c}115 . \\
93\end{array}$ & 38.29 & $\begin{array}{c}167.1 \\
0\end{array}$ & $\begin{array}{c}291.0 \\
2\end{array}$ & $\begin{array}{c}592.6 \\
2\end{array}$ & $\begin{array}{c}0.3 \\
0\end{array}$ & $\begin{array}{c}3321.6 \\
0\end{array}$ & $\begin{array}{c}285.1 \\
2\end{array}$ & $\begin{array}{c}441.3 \\
8\end{array}$ & $\begin{array}{c}204.8 \\
7\end{array}$ & 11.76 & $\begin{array}{c}443.2 \\
8\end{array}$ & $\begin{array}{c}3670 . \\
19\end{array}$ \\
\hline$\underset{5}{\text { S_w1 }}$ & $\begin{array}{c}132 . \\
14\end{array}$ & 942 & $\begin{array}{c}207.9 \\
4\end{array}$ & $\begin{array}{c}491.1 \\
0\end{array}$ & $\begin{array}{c}1083 \\
38\end{array}$ & $\begin{array}{c}0.3 \\
6\end{array}$ & $\begin{array}{c}4105.9 \\
2\end{array}$ & $\begin{array}{c}340.2 \\
1\end{array}$ & $\begin{array}{c}1014 . \\
78\end{array}$ & $\begin{array}{c}535.5 \\
8\end{array}$ & 11.38 & $\begin{array}{c}461.5 \\
4\end{array}$ & $\begin{array}{c}8559 . \\
50\end{array}$ \\
\hline$\underset{5}{\text { S_w3 }}$ & $\begin{array}{c}162 . \\
88\end{array}$ & $\begin{array}{c}156.7 \\
5\end{array}$ & $\begin{array}{c}285.4 \\
7\end{array}$ & $\begin{array}{c}871.2 \\
2\end{array}$ & $\begin{array}{c}2015 . \\
56\end{array}$ & $\begin{array}{c}0.4 \\
7\end{array}$ & $\begin{array}{c}5595.2 \\
9\end{array}$ & $\begin{array}{c}444.8 \\
3\end{array}$ & $\begin{array}{c}2093 . \\
06\end{array}$ & $\begin{array}{c}1163 . \\
14\end{array}$ & 10.61 & $\begin{array}{c}496.1 \\
8\end{array}$ & $\begin{array}{c}17847 \\
.36\end{array}$ \\
\hline S_UK & $\begin{array}{c}114 . \\
94\end{array}$ & 50.00 & $\begin{array}{c}149.1 \\
3\end{array}$ & $\begin{array}{c}215.9 \\
9\end{array}$ & $\begin{array}{c}494.9 \\
4\end{array}$ & $\begin{array}{c}0.3 \\
0\end{array}$ & $\begin{array}{c}3031.4 \\
7\end{array}$ & $\begin{array}{c}266.2 \\
9\end{array}$ & $\begin{array}{c}476.2 \\
8\end{array}$ & $\begin{array}{c}161.1 \\
0\end{array}$ & 11.22 & $\begin{array}{c}436.2 \\
2\end{array}$ & $\begin{array}{c}3171 . \\
11\end{array}$ \\
\hline$\underset{\mathbf{p}}{\text { S_Ex }}$ & $\begin{array}{c}117 . \\
04\end{array}$ & 59.17 & $\begin{array}{c}149.8 \\
5\end{array}$ & $\begin{array}{c}223.4 \\
2\end{array}$ & $\begin{array}{c}538.7 \\
8\end{array}$ & $\begin{array}{c}0.3 \\
0\end{array}$ & $\begin{array}{c}3061.6 \\
2\end{array}$ & $\begin{array}{c}268.8 \\
7\end{array}$ & $\begin{array}{c}567.6 \\
4\end{array}$ & $\begin{array}{c}197.0 \\
5\end{array}$ & 2 & $\begin{array}{c}436.8 \\
1\end{array}$ & $\begin{array}{c}3748 . \\
98\end{array}$ \\
\hline$\underset{\mathbf{K}}{\mathbf{S} \_\mathbf{W}}$ & $\begin{array}{c}111 . \\
94\end{array}$ & 281 & $\begin{array}{c}157.0 \\
5\end{array}$ & $\begin{array}{c}241.7 \\
4\end{array}$ & $\begin{array}{c}471.7 \\
4\end{array}$ & $\begin{array}{c}0.2 \\
9\end{array}$ & $\begin{array}{c}3128.4 \\
2\end{array}$ & $\begin{array}{c}271.5 \\
4\end{array}$ & $\begin{array}{c}299.9 \\
4\end{array}$ & $\begin{array}{c}123.4 \\
0\end{array}$ & 35 & $\begin{array}{c}438.7 \\
9\end{array}$ & $\begin{array}{c}2465 . \\
90\end{array}$ \\
\hline$\underset{\mathbf{x p}}{\text { S_wE }}$ & $\begin{array}{c}113 . \\
16\end{array}$ & 31.26 & $\begin{array}{c}160.1 \\
3 \\
\end{array}$ & $\begin{array}{c}256.8 \\
3 \\
\end{array}$ & $\begin{array}{c}508.7 \\
6\end{array}$ & $\begin{array}{c}0.2 \\
9\end{array}$ & $\begin{array}{c}3187.5 \\
9\end{array}$ & $\begin{array}{c}275.7 \\
0\end{array}$ & $\begin{array}{c}343.3 \\
1 \\
\end{array}$ & $\begin{array}{c}148.3 \\
5\end{array}$ & 11.83 & $\begin{array}{c}440.1 \\
7\end{array}$ & $\begin{array}{c}2834 . \\
68\end{array}$ \\
\hline
\end{tabular}

